\title{
INVITACIÓN AL MATRIMONIO: EN TORNO A UN PASAJE ESTACIANO (SILV. I 2, 161-200)*
}

This paper is a literary commentary of Statius' Siluae I 2, 161-200 (a suasoria to love). The following points are discussed: structure, general and particular sources, stylistic devices and literary fortune. Statius' primary source of inspiration was Vergil's Aeneid IV 31-53 (Anna's suasoria addressed to Dido). But he also elaborated on

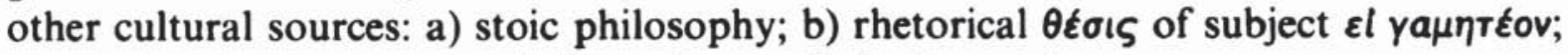
and c) amatory and elegiac poetry.

\section{Texto ${ }^{1}$}

tunc ipsam solo reclinem adfata cubili:

'quonam hic usque sopor uacuique modestia lecti,

o mihi Laurentes inter dilecta puellas?

quis morum fideique modus? numquamne uirili

summittere iugo? ueniet iam tristior aetas.

exerce formam et fugientibus utere donis.

non ideo tibi tale decus uultusque superbos

meque dedi uiduos ut transmittare per annos

ceu non cara mihi. satis o nimiumque priores

despexisse procos. at enim hic tibi sanguine toto

deditus unam omnes inter miratur amatque,

nec formae nec stirpis egens; nam docta per Vrbem

carmina qui iuuenes, quae non didicere puellae?

hunc et bis senos (sic indulgentia pergat

praesidis Ausonii) cernes attollere fasces

ante diem; certe iam nunc Cybeleia mouit

limina et Euboicae carmen legit ille Sibyllae,

iamque parens Latius, cuius praenoscere mentem

fas mihi, purpureos habitus iuuenique curule

* Este trabajo ha sido realizado en el marco del Proyecto de Investigación «Ovidio: Opera amatoria II" (PB82-0486 de la DGICYT). Deseo agradecer a los profesores A. Ramírez de Verger, E. Sánchez Salor, J. Ureña y L. Rivero García sus correcciones y sugerencias críticas.

' Sigo el texto de Courtney (1990), salvo en los lugares indicados en nota. 
indulgebit ebur, Dacasque (et gloria maior) exuuias laurosque dabit celebrare recentes. ergo age iunge toros atque otia deme iuuentae. quas ego non gentes, quae non face corda iugali ${ }^{2}$

* * * * *?

alituum pecudumque mihi durique ferarum non renuere greges; ipsum in conubia terrae aethera, cum pluuiis rarescunt nubila, soluo. sic rerum series mundique reuertitur aetas. unde nouum Troiae decus ardentumque deorum raptorem, Phrygio si non ego iuncta marito? Lydius unde meos iterasset Thybris Iulos? 190 quis septemgeminae posuisset moenia Romae imperii Latiale caput, (ni)si Dardana furto cepisset Martem, nec me prohibente, sacerdos?' his mulcet dictis tacitaeque inspirat amorem ${ }^{3}$ conubii. redeunt animo iam dona precesque et lacrimae uigilesque uiri prope limina questus 'Asteris' ${ }^{4}$ et uati ${ }^{5}$ totam cantata per Vrbemi, 'Asteris' ante dapes, nocte 'Asteris', 'Asteris' ortu, quantum non clamatus Hylas. iamque aspera coepit flectere corda libens et iam sibi dura uideri.

\section{INTRODUCCIÓN Y ESTRUCTURA}

La Silva I 2 de Estacio es un extenso epitalamio que celebra la boda de Lucio Arrencio Estela ${ }^{6}$, patrón del poeta, con una viuda llamada Violentila (la boda debió de celebrarse a principios del año 90 d. C. y Estacio compuso probablemente su epitalamio poco antes, para ser re-

${ }^{2}$ Courtney (1990, p. 12), supone plausiblemente una laguna aquí, siguiendo a los editores Postgate y Saenger. Para subsanar la frase cortada y evitar la laguna, se ha corregido la paradosis iugali a iugaui.

${ }^{3}$ Courtney (1992, p. 13), imprime honorem del manuscrito más antiguo $(M)$. Es preferible amorem, obvia corrección de mss. posteriores, que da mejor sentido y tiene paralelos en Verg., Aen. IV 54 (una clara fuente del pasaje estaciano) y Sil., VII 255.

4 Aquí y en los dos casos siguientes Asteris debe escribirse con comillas (cf. Verg., Ecl. VI 44).

5 Prefiero la corrección uati, impresa por Markland (1827, p. 14) y defendida en p. $180 \mathrm{~b}$, como dativo de agente de cantata (cf. Verg., Georg. III 6 cui non dictus Hylas...?), frente a Courtney (1990, p. 13), que acepta la lectura uatis de los manuscritos.

${ }^{6}$ Para Estela, cf. PIR ${ }^{2}$ A 1151, RE II 1, cols. 1265-66, s.u. Arruntius 26 (P. von Rohden), White 1975, pp. 267-72.

7 Para una puesta al día sobre las Silvas, cf. Cancik (1986) (bibliografia) y Vessey (1986) (estudio). Monografias sobre las Silvas son Cancik (1965), Newmyer (1979), Bright (1980) y Hardie (1983). 
citado en la ocasión). De las 32 composiciones incluidas en los cinco libros de las Silvas ${ }^{7}$, ésta es la que mayor atención crítica ha recibido ${ }^{8}$, conjuntamente con la Silva V 4 (Somnus) ${ }^{9}$. Asimismo, es el poema con mayor influencia ulterior, ya que se erigió en modelo de epitalamios latinos posclásicos (de Claudiano, Sidonio Apolinar, Ennodio, Luxorio, Draconcio y Venancio Fortunato) ${ }^{10}$.

La Silva celebra, al principio y al final (vv. 1-45, 201-277), la ocasión social contemporánea de las nupcias de Estela y Violentila pero, según una técnica habitual en otras Silvas ", Estacio incluye en el centro del poema un largo relato etiológico (aĭrıov) que explica los antecedentes del acontecimiento (vv. 46-200). La naturaleza etiológica de este panel central es mencionada expresamente por Estacio (vv. 46-47: sed quae causa toros... / attulit?, donde causa equivale a altía). Este relato se sitúa en el pasado; se caracteriza por su fuerte componente fantástico y por un estilo épico propio de un epilio. Incluso es introducido por la invocación a la Musa (vv. 46-50).

En el contexto de esta digresión etiológica se inscribe la intervención divina de Venus. La diosa vence las reticencias de la futura novia Violentila mediante una invitación al matrimonio (vv. 161-200) que va a ser el objeto de nuestro análisis.

El pasaje puede estructurarse asi:

1. Exordium: «¿hasta cuándo tu soledad?» (161-165a)

2. Tractatio: razones para casarse (165b-193)

a) Carpe diem: "aprovecha tu juventud" (165b-169a)

b) Laus Stellae (encomio de Estela) (169b-181)

c) Exempla (ilustraciones) (182-193)

a) naturales (182-187)

B) legendarios (188-193)

3. Conclusio: Violentila consiente (194-200)

La estructura propuesta puede justificarse como sigue. En el exordium (161-165a), Venus incide en el tema de "ihasta cuándo tu soledad?» mediante la sucesión de tres cuestiones retóricas sinónimas.

${ }^{8}$ Cf. Herzog (1881), Lohrisch (1905, pp. 61-71), Pavlovskis (1965), Vessey (1972), Vessey (1973, pp. 18-20), Newmyer (1979, pp. 26-31), Hardie (1983, pp. 111 15), Roberts (1989).

9 Para esta Silva, cf. Laguna (1990), con bibliografía en pp. 123-24, n. 6. (1989).

${ }^{10}$ Cf. Morelli (1910), Pavlovskis (1965), Pavlovskis (1972, passim), Roberts

"Para esta técnica, cf. Laguna (1992, pp. 120-21), Bishop (1951, pp. 428-29) y Newmyer (1979, pp. 61-62). 
La tractatio (165b-193) incluye tres argumentos. El primero (165b169a) es la necesidad de aprovechar la juventud (variedad del tópico del carpe diem). A esta sección le confiere unidad la mención del tiempo al principio y al final (165 aetas, 168 annos).

El segundo argumento es el encomio de Estela (169b-181), introducido por la interjección $o$ (v. 169) y por la adversativa enfática at (170); y concluido por una oración ilativa (182 ergo age...). Proporciona unidad interna a esta parte la distribución de (pro)nombres referidos a Estela, con poliptoton y uariatio: 170 hic, 174 hunc, 179 iuuenique.

El tercer y último argumento es un catálogo de exempla o ilustraciones de ámbitos sobre los que Venus extiende su poder (182-193). Estas ilustraciones se dividen, temáticamente, en naturales (182-187) y legendarias (188-193) (en esto, como precisaré, Estacio se inspira en un pasaje de la Phaedra de Séneca). Los exempla naturales arrancan con dos interrogaciones retóricas (183 quas... quae...?) y concluyen con una frase ilativa (187 sic...). Los exempla humanos y legandarios consiguen su unidad gracias a la distribución de cuestiones retóricas, con anáfora y uariatio: 188 unde...? / 190 unde...? / 191 quis...?

\section{FUENTES GENERALES}

Para establecer las fuentes generales de este pasaje, es necesario rastrear en tres ámbitos: la retórica, la literatura y la filosofia.

$\mathrm{La}$ instrucción retórica del nivel educativo superior incluía, desde época helenística, una serie de ejercicios preparatorios de dificultad cre-

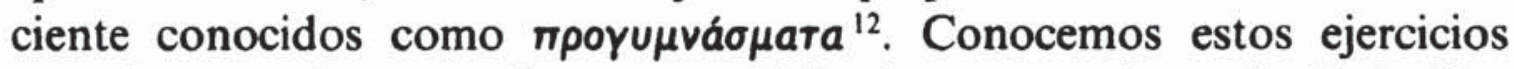
por rétores griegos tardíos, como Teón (contemporáneo de Quintiliano), Hermógenes (fines del siglo II d. C.), Libanio (s. Iv), Aftonio (fines s. Iv) y Nicolao (s. v). Unos de estos ejercicios era la $\theta \dot{\varepsilon} \sigma ı \varsigma$, consistente en la discusión, a favor o en contra, de un postulado general ${ }^{13}$. Pues bien, es significativo que varios rétores enuncien como tema habitual de

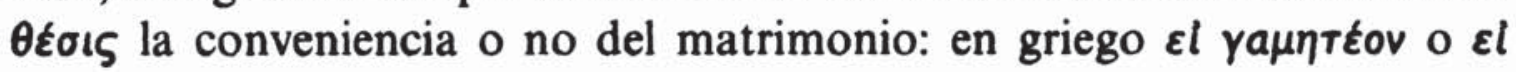

12 Cf. Reichel (1909), Marrou (1965, pp. 259-64), Russell-Wilson (1981, pp. xxvxxix), Reche Martínez (1991, pp. 7-31).

${ }_{13}^{13}$ Citan el ejercicio de la Otoıs Cic., Inu. I 6, 8, De orat. I 31, 138, Orat. XIV 46, Top. LXXIX, Quint., Inst. III 5, 5. Es tratado por Theon, Prog. XII (Spengel 1854 , pp. 120-28), Herm., Prog. XI (Spengel 1854, pp. 17-18), Aphth. XIII (Spengel 1854, pp. 49-53), Nicol., Prog. XIII (Spengel 1856, pp. 493-97). Libanio tiene una colección de ejemplos prácticos de Oéozıs (Foerster 1915). Léase el estudio de Bonner (1969, pp. 2-11). 


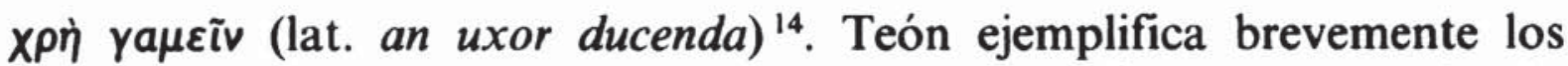

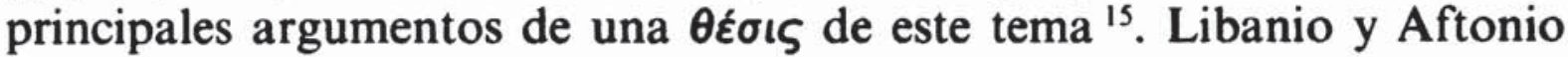
transmiten largos ejemplos de tratamiento de esta $\theta \varepsilon \dot{\varepsilon} \iota^{\prime} \varsigma^{16}$. El problema es que estos preceptistas retóricos son posteriores a Estacio y a otros ejemplos literarios clásicos. Ante este problema, la opinión tradicional era que esos tratados tardíos se remontaban a tratados anteriores, que habrían influido en los ejemplos literarios clásicos. Me inclino a pensar, sin embargo, que hay bastante de lo contrario: los rétores tardíos debieron de teorizar sobre un corpus literario preexistente ${ }^{17}$. Con todo, como no se debe descartar completamente una cierta influencia de la enseñanza retórica en la literatura, señalaré las coincidencias entre el pasaje estaciano y la preceptiva tardía.

Hay una dificultad técnica al considerar el pasaje de Estacio como

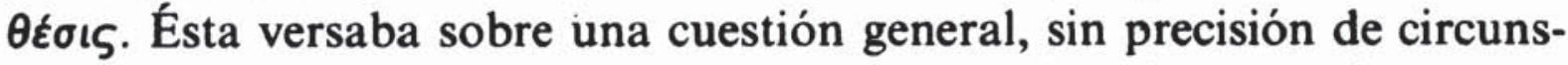
tancias concretas de persona, tiempo o lugar. Si se dan esas circunstan-

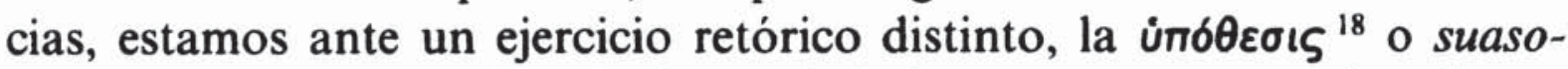

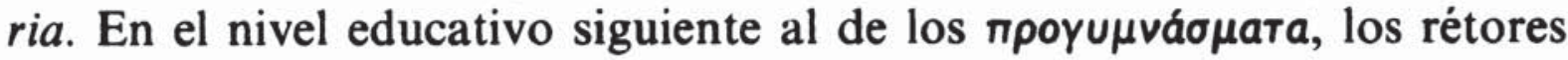
practicaban con los alumnos discursos ficticios, llamados declamationes, de dos tipos: de género deliberativo (suasoriae) y de género judicial (controuersiae). Pero una $\theta \dot{\varepsilon} \sigma \iota \varsigma$ de contenido especulativo puede convertirse fácilmente en suasoria, al ser referida a unas circunstancias concretas. Éste es el caso aquí, donde Venus convence a Violentila de la conveniencia del matrimonio. Por tanto, que el pasaje se defina en un sentido técnico como suasoria no es óbice para que comparta tópicos con la

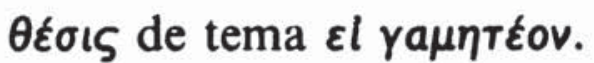

Conviene considerar los precedentes de inclusión de suasoriae de este tema ${ }^{19}$ en obras literarias. Un modelo remoto se encuentra ya en Eurípides: en un agón de la tragedia Hipólito, un sirviente intenta convencer a Hipólito de la conveniencia de venerar a Afrodita (Hipp. 88120). En época helenística, Teócrito nos presenta al cíclope Polifemo re-

${ }^{14}$ Quint., Inst. II 4, 25 (ducendane uxor); III 5, 8 (an uxor ducenda), Theon, Prog. XII (Spengel 1854, p. 120), Herm., Prog. XI (Spengel 1854, p. 17), Aphth. XIII (Spengel 1854, p. 49), Nicol., Prog. XIII (Spengel 1856, p. 494).

is Theon, Prog. XIII (Spengel 1854, p. 125, ll. 13-20).

16 Lib., Thes. XIII (Foerster 1915, p. 550 ss.) y Aphth. XIII (Spengel 1854, pp. 50-53).

17 Cf. Laguna (1992, p. 252 y n. 16).

18 Quint., Inst. III 5, 5-11, Theon, Prog. I (Spengel 1854, p. 61), Hermog., Prog. XI (Spengel 1854, p. 17), y Aphth., Prog. XIII (Spengel 1854, p. 49). Léase Bonner (1969, pp. 8-9).

19 Para algunos ejemplos de adaptaciones literarias de suasoriae de variados temas, cf., sobre Séneca trágico, Canter (1925, pp. 65-66); sobre Ovidio, Bonner (1969, pp. 149-52); y, sobre Propercio, Ramirez de Verger (1989, p. 14). 
quiriendo a la ninfa Galatea (Id. XI). En imitación suya, Virgilio escribe la suasoria de Coridón dirigida a Alexis (Ecl. II 6-55). Pero otro pasaje virgiliano es obviamente el precedente inmediato de Estacio: la suasoria al amor y al matrimonio dirigida por Anna a su hermana Dido (Verg., Aen. IV 31-53). Virgilio inspira a Estacio el planteamiento general, el arranque y la conclusión, y el contraste entre los anteriores pretendientes y el pretendiente actual. Por su parte, el burlón Ovidio ofrece un tratamiento paródico: los consejos de la lena Dípsade a una joven sobre cómo llevar la carrera de la prostitución (Ou., Am. I 8, 23-108). De Ovidio, Estacio toma la alusión al paso del tiempo como argumento para instar al matrimonio. Otro ejemplo de Ovidio, éste de las Metamorfosis, es menos paródico: el pasaje en que el dios Vertumno, disfrazado de anciana, intenta convencer a la ninfa Pomona para que ceda a los requerimientos del propio Vertumno (Met. XIV 654-697, 761-764). Un último modelo que Estacio debió de tener también en cuenta, como referencia general y en varios detalles, es una suasoria de la Phaedra senequiana, inspirada a su vez en Eurípides, dirigida por la nodriza de Fedra a Hipólito (vv. 435-482) ${ }^{20}$.

Pero el tema del pasaje explica que Estacio, en diferentes tópicos, acuse influencias de la poesía erótica anterior (especialmente, elegía y Horacio), en los siguientes tópicos, que serán comentados en su debido

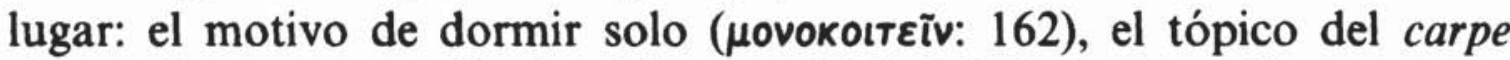
diem y las amenazas hacia el futuro (165b-169a), la devoción amorosa propia del amante elegíaco (170b-171), las hazañas del patrón (174-81) y la descripción del pretendiente como exclusus amator (195b-199).

La última posible influencia cultural en el tema del pasaje estaciano es la de la filosofia estoica. Como es bien sabido, se desarrolló una polémica entre las filosofias estoica y epicúrea en lo concerniente al matrimonio y al enamoramiento. Para Epicuro, el matrimonio y la familia son indeseables, por ser fuentes de preocupaciones. Esta doctrina fue divulgada en Roma por el apóstol de la secta, Lucrecio, y tuvo reflejo literario en autores como Lucilio, Terencio, Virgilio, Horacio y Propercio $^{21}$. En cambio, el estoicismo valoraba positivamente el matrimonio,

${ }^{20}$ Otro pasaje de la Phaedra, sobre el poder universal del Amor (vv. 295-355), inspiró el tema de los exempla de Estacio, incluyendo la partición en ilustraciones naturales y legendarias, como comentaré.

21 Epicuro disuadia del matrimonio y de la procreación de hijos (frs. 525-526 Usener; cf. D. L., X 118-19). Terencio puso en boca de Demeas (personaje que encarna la actitud estoica, frente a su epicúreo hermano Mición, pero que luego se desdice) la invectiva contra el matrimonio y la prole: duxi uxorem: quam ibi miseriam vidi! nati filii, / alia cura (Ad. 867-68). Lucrecio escribió una famosa diatriba contra 
la familia y la procreación de hijos, como acordes con la naturaleza. Bastantes estoicos, incluyendo a Crisipo (con floruit en 232 a. C.) y a Cicerón ${ }^{22}$, coinciden en esta apreciación, aunque el romano Musonio Rufo (antes del 30 d. C.-fines del siglo I d. C.) le dedica el tratamiento

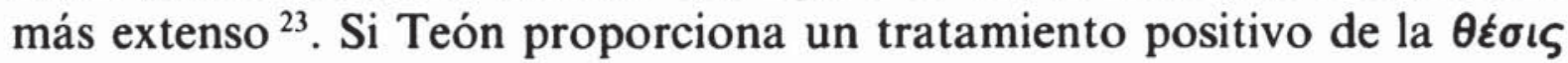
sobre la conveniencia de casarse, es por su talante estoico ${ }^{24}$. Esta actitud estoica tuvo reflejo en la literatura. Por ejemplo, no es de extrañar que la nodriza de Fedra apele a un obvio argumento estoico al final de su suasoria al amor: proinde uitae sequere naturam ducem (Sen., Phaedr. 481). Similares argumentos a favor del matrimonio debió de usar Séneca en su tratado perdido De Matrimonio ${ }^{25}$. El rétor Libanio, en su

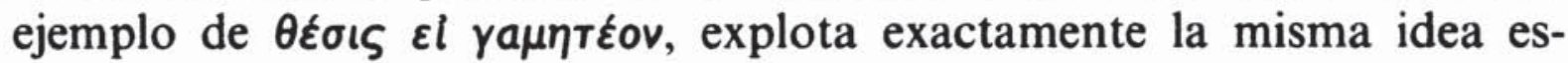
toica $^{26}$. Y el propio Estacio describe la postura estoica ${ }^{27}$ en este aspecto de Claudio Etrusco, alto funcionario al servicio del emperador Domiciano, contraponiéndola con la opción epicúrea (Stat., Silu. III 3, 106110).

\section{Fuentes PARTiculares}

\section{Exordium: «¿hasta cuándo tu soltería?» (161-165a)}

Venus, al presentarse ante Violentila, introduce in medias res su alocución, con dos temas: uno principal, la alusión a la soledad conyugal

el amor, en la que recomienda relaciones con prostitutas sin nexos sentimentales (IV 1057-1191; cf. el estudio de Socas 1985). Horacio comparte la misma actitud (Serm. I 2 y II 7), en imitación de Lucilio (frs. 866-67 Marx). Virgilio, en su égloga II, presenta al pastor Coridón como un trasunto de sabio epicúreo que renuncia al amor (interpretación de Cristóbal López 1980, pp. 328-29). Por último, en dos pasajes de Propercio puede rastrearse una doctrina afin: en su negativa a casarse convencionalmente y procrear hijos (I 7) y en su preferencia por amores con prostitutas (II 23: cf. Ramirez de Verger 1989, p. 152, n. 138).

${ }^{22}$ Crisipo: cf. el testimonio de D. L., VII 121; Cicerón: cf. Fin. III 20, 68.

${ }^{23}$ Pueden leerse los textos de Rufo alusivos en Lutz (1947, pp. 88-96: núms. 1315). Cf. la discusión de Reichel (1909, p. 29), Colish (1990, p. 41) y Dixon (1991, pp. 106-7).

${ }^{24}$ Theon, Prog. XIII (Spengel 1854, p. 125, 1l. 13-20). Este es una de las muchas actitudes estoicas de este rétor que llevan a su identificación con el Teón estoico mencionado en la Suda: cf., sobre su estoicismo, Reichel (1909, pp. 23-30) y, sobre su actitud en pro del matrimonio, Reichel (1909, pp. 29-30) y Martínez (1991, p. 37).

${ }^{25}$ Léase la discusión de Courtney (1980, pp. 252-53).

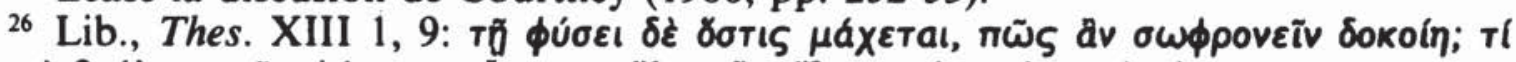

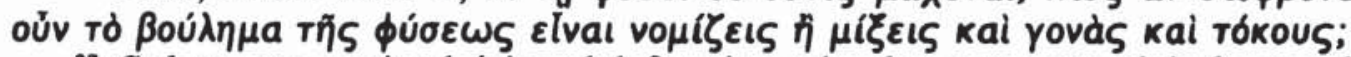

${ }^{27}$ Sobre esta actitud ética del funcionario de corte, propiciada por la cancillería imperial, léase Lotito (1974-75). 
de Violentila; y otro secundario, la mención del cariño que la diosa siente por su pupila. Ambos motivos pueden rastrearse en Virgilio, en el arranque del pasaje que sirvió de modelo a Estacio (Verg., Aen. IV 31-33):

Anna refert: 'o luce magis dilecta sorori, solane perpetua maerens carpere iuuenta nec dulcis natos Veneris nec praemia noris?...'

El inicio del discurso de Anna a Dido (Aen. IV 31: 'o luce magis dilecta sorori!') inspira a Estacio el apóstrofe de Venus a Violentila (v. 163: 'o mihi Laurentes inter dilecta puellas'). Además, este apóstrofe anticipa un tema, el del favor de la diosa por Violentila, que reaparecerá en la suasoria (168 meque dedi, 169 ceu non cara mihi).

El estilo emocional se logra mediante una triple interrogación retórica sinónima con uariatio: 162 quonam... usque...? / 164 quis... modus? / numquamne...? Pues bien, Estacio parece inspirado en el inicio de la primera Catilinaria de Cicerón: Quousque tandem...? / quam diu etiam...? / quem ad finem....? ${ }^{28}$ Ambos arranques comparten el tricolon interrogativo, la uariatio léxica de los introductores interrogativos, la palabra inicial (quousque, con tmesis en Estacio) y el contenido básico. Se aprecia, pues, cómo el componente retórico se manifiesta vivamente desde el principio de la suasoria.

La soledad conyugal de Violentila se expresa con la metonimia del «lecho vacío»: 161 solo... cubili, 162 uacui... lecti, 168 uiduos... annos. El

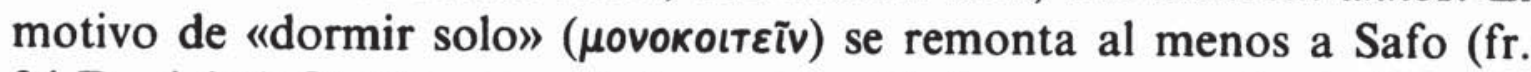

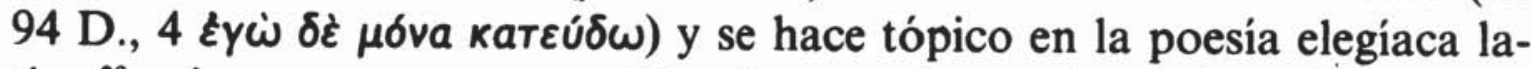
tina ${ }^{29}$, género en que se consideraba una desgracia: cf. hostibus eueniat uiduo dormire cubili / et medio late ponere membra toro! (Ou., Am. II 10, 17-18). Estacio, pues, recurre a un motivo elegíaco para subrayar el tono erótico del pasaje ${ }^{30}$.

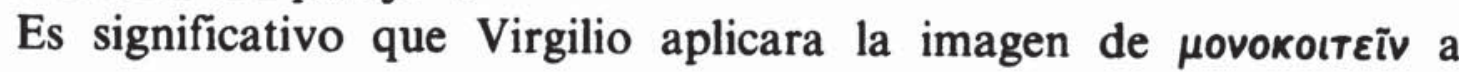

${ }^{28}$ Cf. un arranque similar, con repetición de la noción de "¿hasta cuándo?», en

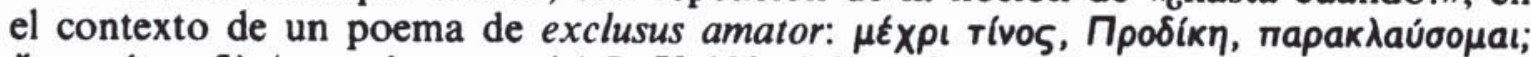
axpı tívos $\delta \dot{\varepsilon} /$ youvdoopal... (A.P. V 103, 1-2). Cf. también Hor., Carm. I 24, 1-2 Quis desiderio sit pudor aut modus / tam cari capitis?

${ }^{29}$ Cf. Catull., VI 6, LXVIII 6; Prop., II 2, 1, II 29, 24, II 33, 41, III 6, 23; Ou., Am. I 2, 2-3, II 9b, 39-40 (con Ramírez de Verger - Socas 1991, p. 62, n. 9), II 10, 17-18, II 19, 42, III 5, 42, Trist. V 5, 48, Epist. XVI 317; Stat., Silu. III 5, 60-61. Léase, sobre el tópico, Giangrande (1974, pp. 34-35), Laguna (1992, p. 373), Pichon (1902, p. 287 s.u. uacuus; p. 293 s.u. uiduus).

${ }^{30}$ El mismo tópico, y con similar intención, se documenta en otro lugar estaciano: Silu. III 5, 60-61. 
Dido, en el momento en que, ya enamorada de Eneas, por las noches se separa del troyano (Verg., Aen. IV 80-83). Ese pasaje bien pudo ser el modelo inmediato de Estacio.

2. Tractatio: razones para casarse (165b-193)

a) Carpe diem: «aprovecha tu juventud» (165b-169a)

El primer argumento en la suasoria de Venus también es amatorio y elegíaco. Venus apela al paso del tiempo para convencer a Violentila de que aproveche su juventud antes de que se marchite (165b-166). Se trata, obviamente, de una variedad del tópico del carpe diem, usado en este caso para incitar al matrimonio ${ }^{31}$. El modelo inmediato de Estacio procede de la irrespetuosa suasoria ovidiana de la lena Dípsade a su pupila (Ou., Am. I 8, 49-53), que incluye la responsión léxica de formam exercere $^{32}$ : forma, nisi admittas, nullo exercente senescit (v. 53).

La frase ueniet iam tristior aetas, por su parte, incorpora un tono encubierto de amenaza, también reminiscente de la poesía erótica, especialmente del género elegíaco. Uno de los lugares comunes del género de la ruptura amorosa (renuntiatio amoris) son las amenazas (minae) del poeta hacia la persona que amó. No es fácil olvidar las amenazas de Catulo a Lesbia, de Propercio a Cintia, de Tibulo a Márato o de Horacio a Lidia y Ligurino ${ }^{33}$. Valgan, como ejemplo, las amenazas de Propercio, donde se leen los mismos lexemas uenire y aetas (III 25, 11-12): at te celatis aetas grauis urgeat annis, / et ueniat formae ruga sinistra tuae!

${ }^{31}$ Precedentes de la misma idea se encuentran en Catull., LXII 48-57, y Sen., Phaedr. 446-80 (cf. v. 446 aetate fruere: mobili cursu fugit). Cf. Laguna (1992, pp. 376-77), ad Stat., Silu. III 5, 68-69. El motivo aparece profusamente en elegía: Prop., I 19, 25-26, II 15, 23-24, IV 5, 59-60; Tib., I 1, 69-74, I 4, 27-40; Ou., Am. I 8, 48-53 (con n. de McKeown 1989, II, pp. 227-228), Ars III 59-88 (el ejemplo más extenso).

32 El sintagma formam exercere evoca también el léxico propio de un epitalamio: Catull., LXI 228 exercete iuuentam.

${ }^{33}$ Catull., VIII 14-18; Prop., III 24, 11-18 (con nn. de Ramírez de Verger 1986, pp. 79-81); Tib., I 9, 79-80 (con nn. de Ramírez de Verger 1987, pp. 342-43); Hor., Carm. I 25 (a Lidia; cf. Nisbet-Hubbard 1970, pp. 289-91), IV 10 (a Ligurino); A.P. V 103 (a Rufino); Ou., Ars III 69-76, Medic. 45-48. Para la tipificación del género de la renuntiatio amoris, véase Cairns 1972, pp. 80-81. 
b) Laus Stellae (encomio de Estela) (169b-181)

El encomio de Estela es introducido por un fuerte contraste entre los anteriores pretendientes y Estela (priores... procos / at... hic...). Esta contraposición parece igualmente inspirada en la antedicha suasoria de Anna a Dido, donde Virgilio usa además el mismo verbo despicio (Verg., Aen. IV 35-38):
esto: aegram nulli quondam flexere mariti, non Libyae, non ante Tyro; despectus Iarbas ductoresque alii, quos Africa terra triumphis diues alit: placitone etiam pugnabis amori?

Pero la combinación priores... procos procede de otra alocución virgiliana puesta en boca de Dido (Verg., Aen. IV 534-36), donde despicio aparece sustituido por su sinónimo dedignor:
'en, quid ago? rursusne procos inrisa priores experiar, Nomadumque petam conubia supplex, quos ego sim totiens iam dedignata maritos?...'

Comparable es también la técnica de Ovidio en la suasoria de Vertumno, disfrazado de anciana, a Pomona. Se contrastan los anteriores pretendientes (Ou., Met. XIV 672-74) con Vertumno (675-78), para ventaja de éste. A continuación, la falsa anciana se embarca en el encomio de Vertumno (679-91), exactamente igual que Venus va a hacer sobre Estela.

El principal argumento de Venus para contrastar a Estela con los anteriores pretendientes es la devoción absoluta y exclusiva de éste hacia Violentila: at enim hic tibi sanguine toto / deditus unam omnes inter miratur amatque (170-71). Exactamente lo mismo argumenta la falsa anciana sobre Vertumno en el pasaje ovidiano: nec, uti pars magna procorum, / quam modo uidit, amat: tu primus et ultimus illi / ardor eris, solique suos tibi deuouet annos (Met. XIV 681-83). El motivo se explica a partir de un doble origen. Por un lado, es la extrapolación al hombre del ideal social de la mujer uniuira ${ }^{34}$ : cf. cum quo uixit ab uirginitate sua ad finem uitae suae (CIL X 3720). Por otra parte, es un tópico literario:

34 Sobre el ideal social de la mujer uniuira, documentado tanto en inscripciones (véanse numerosos ejemplos en Lattimore 1942, p. 296 y n. 251 y en Williams 1958, p. 23) como en literatura (e. g. Catull., CXI 1-2; Hor., Carm. III 14, 5; Prop., IV 11, 36 y 68), cf. Williams (1958, pp. 23-25), Laguna (1989, p. 139), Forbis (1990) y Laguna (1992, pp. 369-70). 
recuérdense las famosas palabras de Propercio a Cintia: tu mihi sola places: placeam tibi, Cynthia, solus (II 7, 20) ${ }^{35}$.

El encomio de Estela es la sección que Estacio desarrolla más, en conexión con la finalidad cortesana del poema, aunque va a ser a la que menos atención prestemos aquí. Baste decir que sigue de cerca las convenciones retóricas ${ }^{36}$. El encomio $(\varepsilon \gamma \kappa \omega \dot{\mu} \mu \iota v)$ era uno de los ejercicios

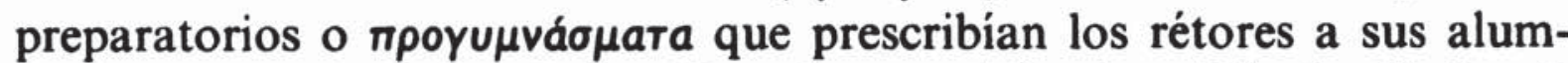
nos, como testimonian Teón, Hermógenes, Aftonio y Nicolao ${ }^{37}$. Igualmente, Menandro tiene un capítulo dedicado al encomio imperial ( $\beta a \sigma t-$

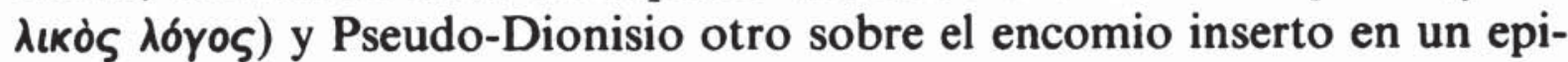

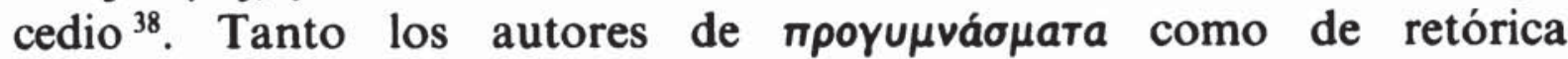
epidíctica presentan listas similares de apartados o tópicos ( $\kappa \varepsilon \phi a ́ \lambda a ı$, тónoı) para el encomio ${ }^{39}$. Podemos tomar como ejemplo la preceptiva de Hermógenes, comparándola con la práctica de Estacio:

Estacio (172-81)

stirps (172)

forma (172)

aptitudes (172b-73)

acciones $(174-81)$
Hermogenes (Prog. 7 [Spengel 1854, p. 12])

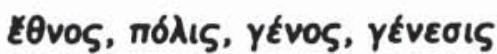

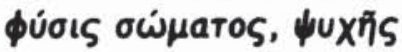

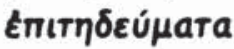

$\pi \rho \dot{a} \xi \varepsilon เ \varsigma$

Es decir, Estacio aborda en su encomio de Estela, y casi en el mismo orden, cuatro de los apartados recomendados por Hermógenes: linaje, hermosura (172 nec formae nec stirpis egens) ${ }^{40}$, aptitudes (172b-73) y acciones (174-81). Las hazañas, a su vez, se distribuyen mediante una composición anular: futuras, auguradas por Venus (174-76a); presentes (176b-177); y, de nuevo, futuras (178-81). La ocupación presente que

${ }^{35}$ Para el tópico de una relación romántica exclusiva, desde la juventud hasta la muerte, cf. Hor., Carm. I 13, 17-20 (con Nisbet-Hubbard 1970, p. 177), III 9, 24; Ou., Am. I 3, 17-18, Epist. V 157-58, Met. VIII 632-33; [Tib.] III 7-8; Stat., Silu. III 5, 23-24 (con Laguna 1992, p. 390). Léase, en general, Dixon (1991).

${ }^{36}$ Para la adecuación de Estacio a la preceptiva epidíctica, cf. Lohrisch (1905, pp. 8-26).

${ }^{37}$ Para diferentes tratamientos del encomio ( $\left.\varepsilon \gamma \kappa \omega \dot{\mu} \mu \iota v\right)$, cf. Theon, Prog. VIII (Spengel 1854, pp. 109-12) con el detallado estudio de Reichel (1909, pp. 89-95) y de Burgess (1902, p. 121); Hermog., Prog. VII (Spengel 1854, pp. 11-14); Aphth., Prog. VIII (Spengel 1854, pp. 35-40); Nicol., Prog. VIII (Spengel 1856, pp. 477-482). Léase Burgess (1902, pp. 118-126) y Russell-Wilson (1981, pp. xxv-xxix).

${ }_{38}$ Men. Rh. 368-377 (léanse las nn. de Russell-Wilson 1981, pp. 271-81) y D. H., Rh. II p. 278 Usener-Radermacher (cf. Newmyer 1979, p. 23).

39 Sobre los tópicos del encomio en Menandro, cf. Pernot (1986).

40 Un sintagma similar lo encontramos en Sal., Catil. XXV, en la descripción de Sempronia: Haec mulier genere atque forma... satis fortunata fuit. 
Venus recuerda es la de quindecimuir sacris faciundis. El cargo futuro que la diosa augura es el de cónsul, expresado mediante metonimias al uso: 174-75 bis senos... fasces, $179-80$ purpureos habitus... curule... ebur. Nótese el detalle encomiástico de que Venus augure el consulado antes de la edad reglamentaria de 43 años (176 ante diem). No sabemos con seguridad si el augurio se cumplió, pues Estela fue nombrado en efecto cónsul suffectus, pero en el año 101, ya en época de Trajano: no puede asegurarse si para entonces tenía más de 43 años. Lo importante es que Estacio manipula aquí el tópico literario del puer-senex (joven cuya valía personal excede lo esperable en su edad), con el modelo de Virgilio: Iulus, / ante annos animumque gerens curamque uirilem (Aen. IX 310$11)^{41}$. Es importante notar que el consulado se concibe como concesión graciosa del emperador Domiciano (174-75 sic indulgentia pergat / praesidis Ausonii, 180 indulgebit, 181 dabit). Y, por supuesto, Estacio no pierde oportunidad para adular a Domiciano mediante los títulos encomiásticos habituales: praesidis Ausonii (175), parens Latius (178) ${ }^{42}$.

Para encomiar al patrón, Estacio le augura por boca de Venus el honor de celebrar el triunfo de Domiciano sobre los dacios (178-81). Se trata, obviamente, de un uaticinium ex euentu, pues Arruncio Estela fue nombrado cuestor el 5 de diciembre del 89: en calidad de tal organizó poco después Juegos en celebración de la victoria de Domiciano sobre los dacios. Literariamente, el tema de las hazañas del patrón y, más específicamente, de su triunfo, es frecuente en elegía ${ }^{43}$.

Concluye esta sección con una apelación: ergo age iunge toros atque otia deme iuuentae (182). La frase iungere toros es una de las perifrasis manieristas para 'casarse', tan queridas a Estacio ${ }^{44}$. Por su parte, el sintagma otia deme iuuentae evoca las palabras de Anna a Dido: solane perpetua maerens carpere iuuenta? (Verg., Aen. IV 32) ${ }^{45}$.

${ }^{41}$ Sobre este tópico, cf. Laus Pis. 259, Stat., Theb. VI 756-57. Estacio aplica el motivo a varios patrones: Silu. II 1, 40 (Glaucias), III 3, 68 (Claudio Etrusco: véase n. en Laguna 1992, p. 276), V 2, 13 (Crispino Vetio).

${ }^{42}$ Sobre estos títulos del emperador en Marcial y Estacio, cf. el estudio de Sauter (1934).

${ }^{43}$ Alusiones al triunfo del patrón o emperador: Tib., I 1, 53-54 (te bellare decet terra, Messalla, marique, / ut domus hostiles praeferat exuuias); Hor., Carm. IV 2, 3360; Prop., III 4, 12-16; Ou., Ars I 177-218. En el propio Estacio, cf. Silu. V 2, 132-51.

${ }^{44} \mathrm{Cf}$. iungere (conciliare) toros (foedera, conubia, taedas, faces); accendere taedas (faces). Para estas perífrasis, cf. Laguna (1992, p. 377).

${ }^{45}$ Cf. también Stat., Silu. III 5, 61 (sobre su hijastra soltera) otia iam pulchrae terit infecunda iuuentae (con $\mathrm{n}$. de Laguna 1992, p. 373) y Theb. V 106b-8. 
c) Exempla (ilustraciones) (182-193)

En su argumentación, Venus presenta una lista de ilustraciones o exempla sobre el poder del matrimonio. Los divide en dos tipos: naturales (182-87) y legendarios (188-93).

El principal argumento de los epitalamios retóricos, según recomendaban Menandro el Rétor y Pseudo-Dionisio ${ }^{46}$, era el $\pi \varepsilon \rho i$ тoũ $\theta \varepsilon$ ũ тoũ

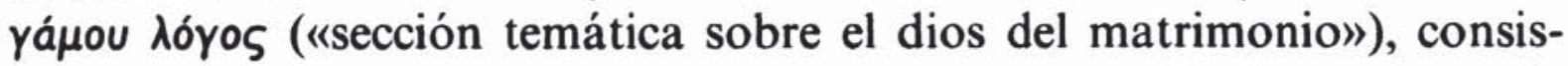
tente en un encomio del dios del amor, y que contenía ilustraciones de dioses, héroes y seres naturales. Pues bien, este tóno procede de las $\theta \dot{\varepsilon}$ -

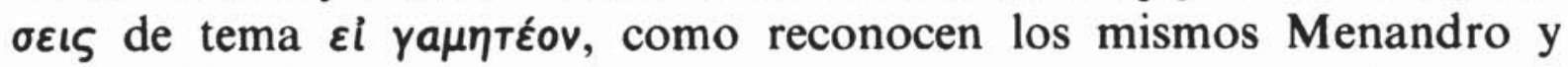
Pseudo-Dionisio ${ }^{47}$. En confirmación de esto, un ejemplo de $\theta \dot{\varepsilon} \sigma \iota \varsigma$, propuesto por Libanio, dedica una sección al matrimonio de dioses y héroes (XIII 1, 3-6), y otra al amor en la naturaleza (XIII 1, 9).

Ahora bien, para la estructura bipartita Estacio contaba con el precedente literario concreto de la Phaedra de Séneca: en la cantata del coro sobre el poder del Amor (274-357) una sección se dedica a dioses y héroes (296-329), seguida inmediatamente por otra sobre la naturaleza (330-357).

\section{a) naturales (182-187)}

Haciendo salvedad del hecho de que, probablemente, hay una laguna textual tras el v. 183, la sección dedicada a los efectos del Amor-Matrimonio sobre los seres naturales incluye a los hombres (183), animales (184-85a) y a la unión de cielo y tierra (185b-86). Todo ello es concluido con una recapitulación (187).

El tema del poder del Amor (o de Venus o del matrimonio) sobre la Naturaleza tiene una larga tradición y puede rastrearse en distintos géneros y épocas, con diferentes intenciones. Es complejo sistematizar un material tan extenso y heterogéneo, pero propongo distinguir tres apartados:

${ }^{46}$ Men. Rh. 400, 29 - 402, 20 enumera los argumentos del $\pi \varepsilon \rho i$ roũ $\theta \varepsilon \circ 0 \tilde{~ r o u ̃ ~ y a ́ \mu o u ~}$

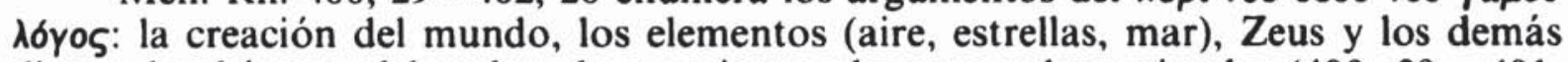
dioses, los héroes, el hombre, las corrientes de agua y los animales (400, $29-401$, 28). El amor implica a ríos, fieras, árboles y dioses $(401,29-402,20)$. Cf. n. de Russell-Wilson (1981, p. 313) ad 400, 32 ss.

Por su parte, Pseudo-Dionisio (Usener-Radermacher 1905, pp. 261-63) menciona como argumentos: a) el origen divino de la institución; y b) la necesidad natural del matrimonio para la perpetuación de las especies.

Este tipo de argumentación tuvo reflejo en los epitalamios griegos de época bizantina: cf. Viljamaa (1968, pp. 127-28).

${ }^{47}$ Men. Rh. 401, 12-16; D. H., Rh. II 261 (Usener-Radermacher 1905, p. 261). 

a) textos hímnicos a Afrodita-Venus (o a Eros-Cupido);
b) ilustraciones sobre los beneficios del amor y del matrimonio incluidas en

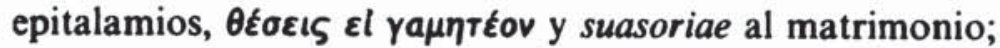
c) descripciones de la universalidad del amor insertas en contextos campestres y bucólicos.

a) El primer apartado es el más productivo ${ }^{48}$. Como es bien sabido, una sección habitual de muchos himnos es la aretalogía, o descripción de los poderes y atributos (ápetaí) del dios invocado ${ }^{49}$. Cuando la aretalogía se refiere a Afrodita o a Eros, suele ser descriptiva de los efectos de tales divinidades sobre la naturaleza. El primer ejemplo, como no podía ser menos, el Himno Homérico a Afrodita (V), desarrolla el tema de los poderes de la diosa en algunas secciones (vv. 1-6, 6974). En cambio, el famoso himno sáfico a Afrodita (fr. 1 L.-P.) no toca la cuestión. Posteriormente sí se documenta el motivo en la tragedia áti$\mathrm{ca}^{\mathrm{so}}$, en un fragmento antológico de Sófocles, de sede incierta (fr. 941) ${ }^{51}$. Otro texto de Sófocles, un coro de la Antígona, vuelve sobre el tema de la universalidad de Eros (vv. 781-90) ${ }^{52}$ :

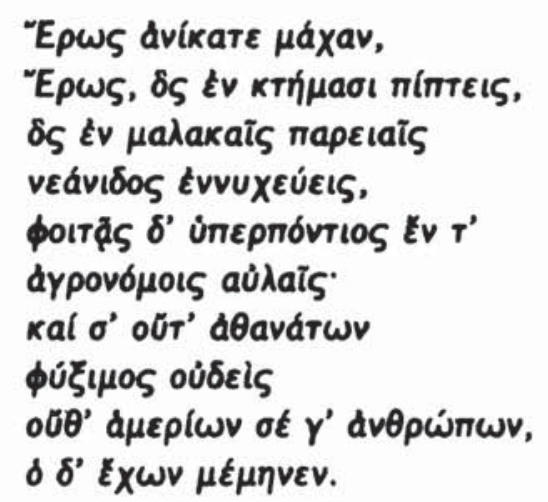

Se aprecia aquí el tema de la universalidad del Amor sobre animales

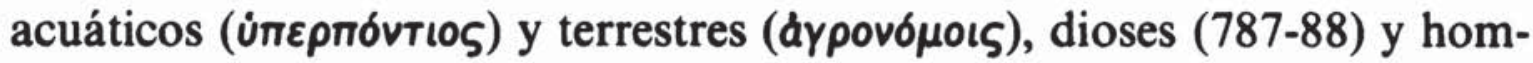

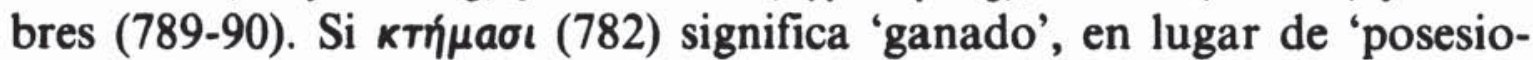

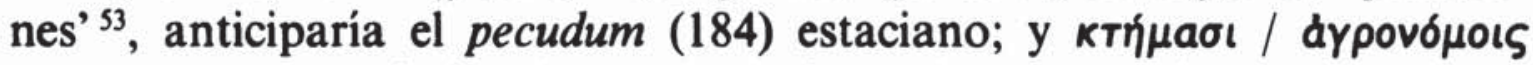

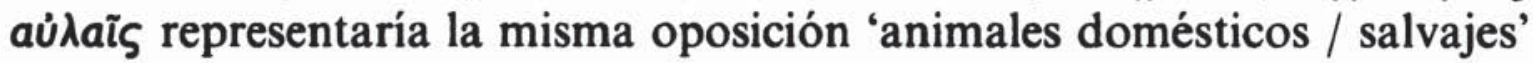
que pecudumque / durique ferarum... greges.

48 Cf. Fischer (1973), Fliedner (1974), Müller (1980) y Carson (1986).

49 Para el himno el locus classicus es Norden (1913, pp. 149-76).

so Cf. Kamerbeek (1978, pp. 143-46).

s1 Texto con comentario en Radt (1977, pp. 589-91).

${ }^{2}$ Cf. los estudios de Müller (1967, pp. 170-76), Castiglioni (1954), y, sobre todo, el completísimo y reciente ensayo de Lasso de la Vega (1990) que, sin embargo, difiere sustancialmente de la interpretación apuntada aquí. Este autor introduce dos

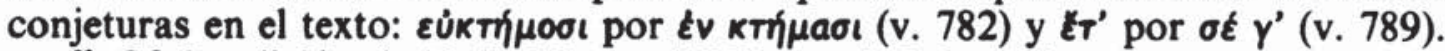

${ }^{33}$ Cf. la edición de Dain-Mazon (1967, pp. 102-3, n. 1). 
Por último, el tema se documenta repetidas veces en el Hipólito de Eurípides: en las palabras de la nodriza de Fedra (443-58) se incluye la ilustración de los amores divinos de Zeus por Sémele, y de la Aurora por Céfalo. En un coro (525-64) se ofrece el exemplum legendario de Hércules y Yolao. Otro coro alude en general al poder de Afrodita sobre dioses, hombres y animales (1268-81). Estas secciones debieron de ser la fuente inmediata de inspiración para que Séneca incluyera el motivo en su Phaedra.

En el mismo nivel genérico está el famoso himno de Lucrecio a Venus, que trata la misma idea de los efectos de Venus sobre la Naturaleza (I 1-43).

En la Phaedra de Séneca, el coro pronuncia un largo himno a Venus y Cupido (274-357), sobre el poder universal de éste. Se divide así: 1) poder universal de Cupido (274-95); 2) ilustraciones divinas: Apolo, Júpiter, la Luna y Hércules (296-329); y 3) ilustraciones naturales: efectos del amor en los animales (330-57). En esta última sección, Séneca reescribe el tratamiento de Eurípides en su Hipólito, combinándolo con el pasaje virgiliano relativo al celo sexual de los animales ${ }^{54}$, que consideraré abajo.

Mención especial merece el Peruigilium Veneris, un extraordinario poema ${ }^{55}$ de datación incierta (quizá del siglo II d. C.), que constituye prácticamente un himno a Venus y desarrolla una sección de áperal de la diosa (59-88), con efectos sobre el universo (59-68), el campo (76-79) y los animales (81-88). Más concretamente, este poema aborda dos secciones coincidentes con Estacio, como trataré más en detalle: la intervención de Venus en uniones de la leyenda de Roma (69-74); y el motivo de las nupcias del cielo y la tierra (59-62).

b) Similares descripciones sirven como ilustraciones en defensa del

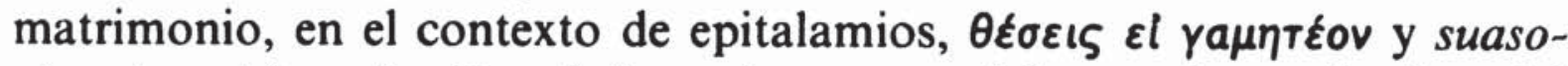
riae al matrimonio. Recuérdense los versos del coro de muchachos del epitalamio catuliano (Catull., LXII 49-58).

En la suasoria al amor de la nodriza de Fedra a Hipólito (Sen., Phaedr. 435-82) se presentan también ilustraciones de elementos naturales: vegetales (455-58), bajo inspiración del epitalamio catuliano; y animales (466-74).

Vertumno disfrazado de anciana usa también el argumento vegetal del emparramiento de la vid y el olmo, en su suasoria a Pomona, ins-

${ }^{54}$ Cf. Boyle (1988, p. 94).

ss Cf. Herzog-Lebrecht Schmidt (1989, pp. 258-263). 
pirándose en el epitalamio de Catulo. La ilustración es especialmente relevante para una ninfa vegetal (Ou., Met. XIV 661-68).

Ya he comentado cómo los teóricos de retórica epidíctica (Menandro el Rétor y Pseudo-Dionisio) recomiendan este argumento en los epitalamios, y cómo ellos mismos reconocen que el tónos procede de las

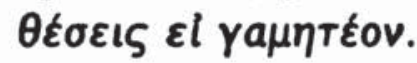

c) El último apartado que hemos de considerar es el de las alusiones a la universalidad del amor insertas en contextos campestres. Habría que distinguir a su vez tres subapartados: i) poesía bucólica; ii) descripciones de la primavera; y iii) contextos agrícolas.

i) En la poesía bucólica, el tema del amor en la Naturaleza sirve como correlato objetivo del amor de los pastores. El tema parte de Teócrito (X 30-31), que inspiró a Virgilio (Ecl. II 63-65) y reaparecerá a su vez en Nemesiano ( $E c l$. IV 26-30) ${ }^{56}$. Véanse los versos de Virgilio:

torua leaena lupum sequitur, lupus ipse capellam,

florentem cytisum sequitur lasciua capella,

te Corydon, o Alexi: trahit sua quemque uoluptas.

ii) También en este apartado hemos de incluir las descripciones de la primavera. El tema se documenta en Lucrecio, Catulo, Horacio, Virgilio, Ovidio, Columela, el Peruigilium Veneris y en el De aduentu ueris de Pentadio ${ }^{57}$. Sin embargo, estas descripciones nos interesan cuando en ellas se identifica la estación primaveral con Venus o Cupido. Esto se da en Lucrecio, que concibe la llegada de la primavera como resultado de los poderes de Venus (I 1-43); en Ovidio (Fast. IV 125 nec Veneri tempus quam uer erat aptius nullum); y en Columela, que, basándose especialmente en Lucrecio y Virgilio, introdujo el tema como pincelada inserta en su descripción de la primavera (X 212-214):

\footnotetext{
hinc maria, hinc montes, hinc totus denique mundus uer agit, hinc hominum, pecudum uolucrumque Cupido atque amor ignescit menti saeuitque medullis.
}

Virgilio, por su parte, tiene un importante pasaje de descripción de la primavera (Georg. II 323-45), en el que sin embargo no menciona ni a Venus ni a Cupido. Ahora bien, en este pasaje introduce precisamente

56 Para un estudio del tema, léase Cristóbal López (1980, pp. 378-82).

57 Cf. Lucr., I 1-40; Catull., XLVI; Hor., Carm. I 4, IV 7 y IV 12; Verg., Georg. II 323-45; Ou., Fast. IV 125-32; Colum., X 212-14; Peruig. Ven. y el De aduentu ueris de Pentadio. Para este tema, cf. Arcaz (1989). 
el motivo de la unión del cielo y la tierra, que reaparece en Estacio, como en seguida recordaré.

iii) Por último, a un contexto agrícola pertenece la descripción virgiliana del celo en los animales (Georg. III 242-283), que empieza así (vv. 242-44):

Omne adeo genus in terris hominumque ferarumque et genus aequoreum, pecudes pictaeque uolucres, in furias ignemque ruunt: amor omnibus idem.

Tras haber presentado estos ejemplos del tema, conviene conjeturar las fuentes de Estacio. La fraseología "técnica" y el contenido de alituum pecudumque mihi durique ferarum / ... greges (184-85) se basan en Lucrecio, a través de Virgilio ${ }^{58}$.

Por otro lado, el motivo concreto de la cópula del cielo y la tierra (185b-86) es un manido tópico que se remonta a Esquilo y Eurípides (dos pasajes que se convirtieron en piezas de antología) ${ }^{59}$. Fue luego tratado por Lucrecio (probablemente inspirado en Esquilo), Cicerón, Virgilio, Estacio (aquí) y el Peruigilium Veneris ${ }^{60}$. Para la época de Tertuliano (c. $160-c .225$ d. C.), el tema se consideraba trillado ${ }^{61}$. A posteriori de los ejemplos literarios, el rétor Menandro recomienda el tópico como ingrediente del epitalamio ${ }^{62}$. Los tratamientos más relevantes para Estacio son los de Lucrecio y Virgilio:

postremo pereunt imbres, ubi eos pater aether

in gremium matris terrai praecipitauit;

(Lucr., I 250-51)

58 Cf. Lucr., I 4 genus omne animantum, 12 aeriae... uolucres, 14 ferae pecudes; 162-63 squamigerum genus et uolucres... / armenta atque aliae pecudes, genus omne ferarum; II 342-44 genus humanum mutaeque natantes / squamigerum pecudes et laeta armenta feraeque / et uariae uolucres. Para la influencia terminológica y formal de Lucrecio en las Geórgicas, cf. Thomas (1988, vol. I, p. 4). Para algunos ejemplos de influencia de Lucrecio en las Silvas de Estacio (un tema bastante descuidado), cf. Lucr., IV 1177-79 Silu. I 2, 196 (véase abajo en este trabajo); Lucr., VI 1140 Silu. III 5, 73 (con n. de Laguna 1992, p. 378); Lucr., I 127-35, V 751-782 (et saepius) Silu. V 3, 19-28 (léase el estudio de Duret 1980).

59 Cf. Aesch., fr. 44 N. (Danaides), con nn. de Radt (1985, pp. 159-60), y Eurip., fr. 839 N. (Crisipo).

${ }^{60}$ Lucr., I 250-51, II 991-97; Cic., Cato 51; Verg., Georg. II 325-27 (con n. de Thomas 1988, vol. I, pp. 215-16); Stat., Silu. I 2, 185-86; Peruig. Ven. 59-62.

${ }^{61}$ quis enim non caelum et terram matrem ac patrem uenerationis et honoris gratia appellet? (Tert., Apol. X).

${ }^{62}$ Men. Rh. 408, 16-19 (con n. de Russell-Wilson 1981, p. 321). 
tum pater omnipotens fecundis imbribus Aether coniugis in gremium laetae descendit, et omnis magnus alit magno commixtus corpore fetus.

(Verg., Georg. II 325-27)

Por último, el verso que recapitula esta sección (187 sic rerum series mundique reuertitur aetas), alusivo a la regeneración cíclica de la naturaleza, se inspira en Horacio (Carm. IV 7, 13 damna tamen celeres reparant caelestia lunae) y en el pasaje de la Phaedra senequiana citado antes (Sen., Phaedr. 466-74).

\section{B) legendarios (188-193)}

Los teóricos como Menandro el rétor y Pseudo-Dionisio recomendaron introducir historias de dioses y héroes en los epitalamios, como

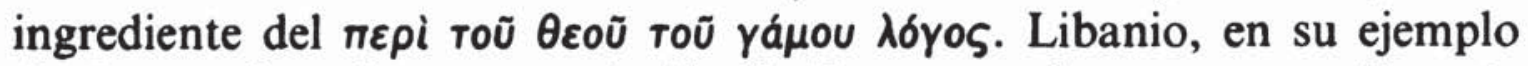
de $\theta \dot{\varepsilon} \sigma ı \varsigma$, sigue la recomendación ${ }^{63}$. Venus concluye con una lista de tres ilustraciones legendarias, alusivas al origen legendario de Roma y, como no podía ser menos, inspiradas en la Eneida. Estacio procede, como es habitual en él, mediante perifrasis eruditas ${ }^{64}$, sin mencionar explícitamente a los aludidos. Cada una de las cuestiones retóricas va introducida por un término interrogativo, con anáfora y uariatio: unde...? unde...? quis...?

La primera interrogación (188-89) alude a Eneas, nacido de la unión de Anquises y la propia Venus, y está llena de ecos de la Eneida. La frase nouum Troiae decus (188) es una perifrasis para Roma, entendida como una nueva Troya: cf. illic fas regna resurgere Troiae (Verg., Aen. I 206). Por su parte, ardentumque deorum / raptorem (188-9), "salvador de los penates en llamas», alude a Eneas, parafraseando Phrygiique penates, / quos mecum a Troia mediisque ex ignibus urbis / extuleram (Verg., Aen. III 148-50) ${ }^{65}$. Phrygio... marito es también una juntura leída en la Eneida, aunque Virgilio la aplicó a Eneas en lugar de a Anquises (IV 103).

La segunda ilustración (190) es de interpretación más dificil: «¿Cómo habría devuelto el lidio Tíber a mis Julos»? Los «Julos» serían Rómulo y Remo, llamados así como descendientes de Eneas (y, por

${ }^{63}$ Men. Rh. 402, 10-15, D. H., Rh. II p. 264 (Usener-Radermacher). Libanio dedica sendos capítulos a dioses (Lib., Thes. XIII 1,3) y héroes (XIII 1, 5).

${ }_{64}$ Cf. Laguna (1992, p. 322).

65 Para el verbo rapio, compárese Verg., Aen. I 378 sum pius Aeneas, raptos qui ex hoste penatis / classe veho mecum, V 632 rapti nequiquam ex hoste penates. 
tanto, parientes de Julo). Cuando la vestal Ilia, preñada de Marte, los alumbró, el tío de ésta, Amulio, ordenó que fueran arrojados al Tíber. Pero el río sufrió una crecida y depositó en la orilla la canasta que los contenía ${ }^{66}$. Iterasset alude a esta acción del río "devolviendo" a tierra a los gemelos, como contó ya Ovidio: [Numitor] amne iubet mergi geminos. scelus unda refugit: / in sicca pueri destituuntur humo (Fast. III 5152). Por su parte, Lydius... Thybris es, asimismo, juntura virgiliana (Aen. II 781-82).

La última ilustración (191-93) es corolario directo de la anterior. Estacio presenta a Rómulo ya crecido y como fundador de Roma. La fuente es de nuevo la Eneida (I 272-77).

La idea de esta serie de ilustraciones legendarias pudo venir sugerida a Estacio por un catálogo de exempla que Ovidio insertó en una suasoria comparable, no para instar al matrimonio, sino para disuadir de la práctica del aborto ( $A m$. II 14). Se trata de un triple exemplum que incluye a Aquiles (hijo de Tetis y Peleo), Rómulo (hijo de Ilia y Marte) y Eneas (hijo de Venus y Anquises): encontramos, pues, dos coincidencias de tres con Estacio (Am. II 14, 13-18).

También el Peruigilium Veneris presenta similares exempla para ilustrar los poderes de Venus $(69-74)^{67}$ :

ipsa Troianos nepotes in Latinos transtulit, ipsa Laurentem puellam coniugem nato dedit, 70 moxque Marti de sacello dat pudicam uirginem, Romuleas ipsa fecit cum Sabinis nuptias. unde Ramnes et Quirites proque prole posterum Iulium mater crearet et nepotem Caesarem.

3. Conclusio: Violentila consiente (194-200)

Con su suasoria, Venus logra vencer la resistencia de Violentila. La conclusión es también reminiscente del éxito de la suasoria virgiliana de Anna a Dido: his mulcet dictis tacitaeque inspirat amorem / conubii (194-95) His dictis impenso animum flammauit amore (Verg., Aen. IV 54).

${ }^{66}$ La anécdota habia sido tratada por Ennio en sus Annales, en el famoso episodio del "sueño de Ilia» (Ann. 35-51 V.: cf. Skutsch 1985, pp. 193-202) y, después, por Horacio (Carm. I 2, 13-20: cf. Nisbet-Hubbard 1970, p. 26) y Ovidio (Am. III 6, 4582, Fast. III 9-52).

${ }^{67}$ El texto del v. 74 es discutido. Imprimo la propuesta de Davis (1992). 
Lo que hace cambiar a Violentila es el recuerdo del cortejo de Estela. Aquí el léxico evoca de nuevo los tópicos de la poesía amatoria, especialmente elegíaca: cf. 195 redeunt animo iam dona precesque Prop., I 1, 16 tantum in amore fides et benefacta ualent. En primer lugar, Violentila recuerda a Estela en su faceta de exclusus amator, con todo el aparato tradicional (ofrendas al umbral, vigilia, llanto, quejas) ${ }^{68}$. Una posible fuente inmediata de inspiración fue el relato ovidiano de la ronda de Ifis a Anaxarte (Ou., Met. XIV 668-764), que el dios Vertumno, disfrazado de anciana, usa como exemplum para convencer a Pomona.

En sus rondas como exclusus, Estela cantó repetidas veces a Violentila, nombrándola bajo el pseudónimo poético de Astéride. Encubrir a la amada bajo un pseudónimo es una práctica elegíaca habitual ${ }^{69}$; la repetición del nombre, por otro lado, nos recuerda el estilo patético de los epilios neotéricos ${ }^{70}$, tal como se refleja también en la égloga VI de Virgilio $^{71}$, que anticipa a Estacio en la repetición del nombre y en el uso de clamare (43-44). Valerio Flaco retomaría la técnica:

\begin{abstract}
his adiungit, Hylan nautae quo fonte relictum clamassent, ut litus 'Hyla, Hyla' omne sonaret; ${ }^{72}$

(Verg., Ecl. VI 43-44)

rursus Hylan et rursus Hylan per longa reclamat auia; responsant siluae et uaga certat imago
\end{abstract}

(V.F., III 596-97)

${ }^{68}$ Los representantes más claros del género exclusus amator, tras la alusión de Lucr., IV 1177-79, son Catull., LXVII (cf. Laguna 1988); Prop., I 16 (cf. el estado de la cuestión sobre el género en Fedeli 1980, pp. 363-67); Hor., Carm. I 25, III 10, y Ou., Am. I 6 (con McKeown 1989, pp. 121-23 y Ramírez de Verger-Socas 1991, pp. 12-13). Para el género, cf. Copley (1956), Nisbet-Hubbard (1970, pp. 289-92), Cairns (1972, pp. 75-76) y Yardley (1978).

Motivos del género aludidos en Estacio: umbral (cf. Ou., Am. I 6, 64 y passim, Pichon 1902, pp. 189 s.u.), quejas (cf. Prop. I 16, 14; 39), vigilia (cf. Prop., I 16, 14, Hor., Carm. III 7, 7-8, Ou., Am. I 6, 7), llanto (cf. Prop., I 16, 4, Ou., Met. XIV 708 y 734).

69 Según la siguiente ecuación: si el poeta elegíaco es Stella (= 'Aorŕp), su amada

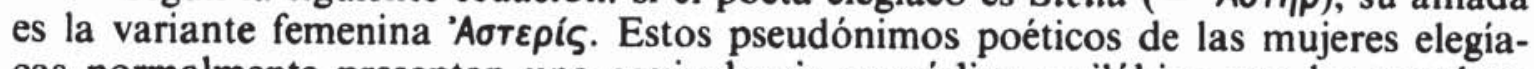
cas normalmente presentan una equivalencia prosódica y silábica con los nombres reales, según estableció R. Bentley: Lèsbiă $=$ Clōdīă (Catulo), Lycōris $=$ Cythēris (Cornelio Galo), Licymniă = Těrentǐ̆ (Hor., Carm. I 2, 64). Cf. Fraenkel (1957, p. 62).

${ }^{70}$ Para repeticiones similares que confieren patetismo al estilo, cf. Verg., Georg. IV 525-27 (Euridicen, repetido tres veces) y los ejemplos citados por Vollmer (1898, p. 255).

${ }_{71}$ Cf. De Echave-Sustaeta (1973, pp. 261-272).

72 Para la historia de Hilas, favorita de los autores griegos alejandrinos y latinos neotéricos, cf. Laguna (1992, p. 322). 
Por último, la alusión a la dureza intransigente de la amada (199200) también es propia de la poesía amatoria y elegiaca. Los adjetivos dura y aspera son habituales de la domina elegíaca ${ }^{73}$ : cf. mihi cum domina proelia dura mea (Prop., III 5, 2), sub cantu querulae despice tibiae / et te saepe uocanti / duram difficilis mane (Hor., Carm. III 7, 30-32). El poeta elegíaco se esfuerza por doblegar (flectere) esa soberbia: cf. flectitur assiduis certa puella minis (Prop., I 19, 24).

\section{CONClusiones}

El pasaje se desarrolla como un interesante ejercicio de alquimia literaria.

Primariamente se plantea como la aplicación literaria del ejercicio retórico de la suasoria, con una estructuración nítida en exordium, tractatio (dividida en tres argumentos) y conclusio.

El punto de partida es la suasoria de Anna a Dido en el libro IV de la Eneida. En conexión con esto, es posible documentar otras reminiscencias y ecos literarios de la Eneida.

En la sección de ilustraciones, Estacio conjuga diferentes modelos: especialmente Lucrecio, Virgilio y Séneca.

Por último, para enriquecer la temática amorosa del paisaje, Estacio recurre a numerosísimos ecos de detalle (en tema y fraseología) de la poesía amatoria anterior, especialmente elegíaca.

\section{Epillogo}

Omnia mutantur, nihil interit ${ }^{74}$. La materia literaria ni se crea ni se destruye, sino que se renueva al verterse en nuevos moldes. Recuérdese el auge que tomaría en nuestra poesía de los Siglos de Oro el tema del carpe diem, uno de los argumentos usados en el texto estaciano (165b69a). Más en concreto, los versos 182-187 de esta Silva I 2 fueron traducidos tempranamente al español por Francisco Cascales y publicados en 1634 , según la noticia de $\mathrm{M}$. Menéndez Pelayo ${ }^{75}$. Por otro lado, un soneto de Lope Félix de Vega Carpio (1562-1635), el XIV de Rimas humanas (1602), es una suasoria al amor similar en intención y temas al

${ }^{73}$ Dura: Pichon (1902, p. 136); aspera: Pichon (1902, p. 91); flectere: Pichon (1902, p. 150).

${ }^{74}$ Ou., Met. XV 165.

${ }^{75}$ Cf. Menéndez Pelayo (1950, pp. 332-333) y Laguna (1992, pp. 43-44). 
pasaje estaciano (sin que la similitud implique necesariamente una influencia directa):

Vierte racimos la gloriosa palma y sin amor se pone estéril luto;

Dafne se queja en su laurel sin fruto, Narciso en blancas hojas se desalma.

Está la tierra sin la lluvia en calma,

viles hierbas produce el campo enjuto;

porque nunca pagó al amor tributo, gime en su piedra de Anaxarte el alma.

Oro engendra el amor de agua y de arenas;

porque las conchas aman el rocio, quedan de perlas orientales llenas.

No desprecies, Lucinda hermosa, el mío, que al trasponer del sol, las azucenas pierden el lustre y nuestra edad el brío.

Una lista de exempla (vv. 1-11) precede a la invitación a gozar del amor (vv. 12-14). Las ilustraciones se alternan entre naturales (1-2, 5-6, 9-11) y legendarias (3-4, 7-8). Todo esto lo hemos comentado en Estacio. Las ilustraciones legendarias son alusivas a leyendas contadas en las Metamorfosis de Ovidio ${ }^{76}$. Veamos las posibles fuentes de los exempla naturales: la ilustración de la vid emparrada (1-2) parece deudora de los pasajes citados de Catulo (LXII 49-58) y Ovidio (Met. XIV 661-68); la imagen de la fecundación de la tierra por la lluvia (5-6) fue usada por el propio Estacio (Silu. I 2, 185b-86). La descripción de la belleza de la amada es reminiscente de Estacio (Lope $12 \sim$ Stat. 166). Tanto Lope como Estacio comentan la actitud despectiva de la mujer (Lope 12 «No desprecies...» Stat. 169-70 satis o nimiumque priores / despexisse priores). Por último, la invitación al goce presente (12-14) contiene un tono de amenaza comparable al de Estacio (Silu. I 2, 165b-66): Lope 14 «nuestra edad [pierde] el brío» Stat. 165 ueniet iam tristior aetas.

Gabriel Laguna Mariscal

${ }^{76}$ Dafne: Ou., Met. I 452-567; Narciso: I 339-510; Anaxarte: XIV 698-764. 


\section{BIBLIOGRAFÍA CITADA}

Arcaz Pozo, Juan Luis (1989): «En torno al De adventu veris de Pentadio», CFC 23 , pp. 157-169.

Billerbeck, Margarethe (1986): «Aspects of stoicism in Flavian epic», en F. Cairns (ed.), Papers of the Liverpool Latin Seminar, Fifth Volume, 1985, Liverpool, Francis Cairns, pp. 341-356.

Bishop, J. H. (1951): "The debt of the Silvae to the Epyllia», Parola del Passato 6, pp. 427-32.

Bonner, S. F. (1969): Roman declamation in the late Republic and early Empire, Liverpool, University Press.

Boyle, Anthony James (1988): "Senecan tragedy: twelve propositions", en A. J. Boyle (ed.), The imperial Muse. Ramus essays on Roman literature of the Empire. To Juvenal through Ovid, Victoria (Australia), Aureal Publications, pp. 78-97. Cf. mi reseña en EMERITA 49, 2, 1991, p. 392.

Bright, David F. (1980): Elaborate disarray: the nature of Statius' Silvae (Beiträge zur klassischen Philologie 108), Meisenheim, Anton Hain.

Burgess, Theodore C. (1902): Epideictic literature (Studies in Classical Philology III), Chicago, The University of Chicago Press (reimp. Ann Arbor 1984).

Cairns, Francis (1972): Generic composition in Greek and Roman poetry, Edimburgo, Francis Cairns.

Cancik, Hurbert (1965): Untersuchungen zur lyrischen Kunst des P. Papinius Statius, Hildesheim, Spudasmata 13.

Cancik, Hurbert (1986): «Statius, 'Silvae'. Ein Bericht über die Forschung seit Friedrich Vollmer (1898)», ANRW II 32, 5, pp. 2681-2726.

Canter, Howard Vernon (1925): Rhetorical elements in the tragedies of Seneca (University of Illinois Studies in Language and Literature 10), Urbana (Illinois), University of Illinois.

Carson, A. (1986): Eros the bittersweet: an Essay, Princeton, University Press.

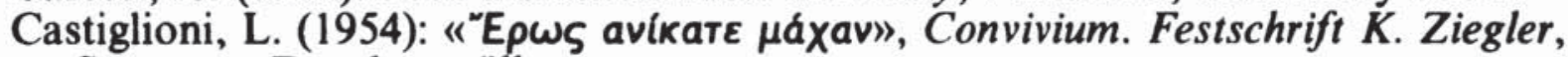
Sttutgart, Druckenmüller.

Coffey, Michael and Roland Mayer (1990): Seneca. Phaedra, Cambridge, University Press.

Colish, Marcia L. (1990): The Stoic tradition from Antiquity to the early Middle Ages. 1. Stoicism in classical Latin literature, Leiden-Nueva York-Copenhague-Colonia, E. J. Brill.

Copley, F. O. (1956): Exclusus amator. A study in Latin love poetry, Baltimore.

Costa, C. D. N. (1973): Seneca. Medea, Oxford, Clarendon Press.

Courtney, Edward (1990): P. Papini Stati Siluae, Oxford, Clarendon Press.

Cristóbal López, Vicente (1980): Virgilio y la temática bucólica en la tradición clásica, Tesis Doctoral, Universidad Complutense de Madrid.

Dain, Alphonse (ed.) et Paul Mazon (tr.) (1967): Sophocle. Tome I. Les Trachiniennes-Antigone, París, Société d'Edition "Les Belles Lettres".

Davis, P. S. (1992): "The text of Pervigilium Veneris 74», CR 42, pp. 575-577.

Day, Archibald A. (1938): The origins of Latin love-elegy, Oxford, Basil Blackwell (reimp. Hildesheim-Zurich-Nueva York, Georg Olms, 1984).

De Echave-Sustaeta, J. (1973): «Virgilio desde dentro: dos claves de estilo en las "Eglogas"", EC 69-70, pp. 261-289.

Dixon, Suzanne (1991): "The sentimental ideal of Roman family", en Beryl Rawson (ed.), Marriage, divorce and children in ancient Rome, Oxford, Clarendon Press, pp. 99-113.

Duret, Luc (1980): «De Lucrèce aux Silves de Stace» (A propos des Silves, V, 3, 19-28)", REL 58, pp. 344-62.

Fasce, Susana (1977): Eros: la figura e il culto, Génova, Università. 
Fedeli, Paolo (1980): Sesto Properzio. Il primo libro delle Elegie, Florencia, Leo S. Olschki.

Fedeli, Paolo (1983): Catullus' Carmen 61, Amsterdam, J. C. Gieben.

Fischer, Edith (1973): Amor und Eros. Eine Untersuchung des Wortfeldes 'Liebe' im Lateinischen und Griechischen, Hildesheim, Gerstenberg.

Fliedner, Heinrich (1974): Amor und Cupido. Untersuchungen über den römischen Liebesgott, Meisenheim an Glan.

Foerster, R. (1915): Libanii opera, vol. 8, Leipzig, Teubner.

Forbis, E. P. (1990): "Women's public image in Italian honorary inscriptions", AJPh 111, pp. 493-512.

Fraenkel, Eduard (1957): Horace, Oxford, Clarendon Press.

Giangrande, Giuseppe (1974): "Los tópicos helenísticos de la elegía latinà, EMERITA 42, pp. 1-36.

Hardie, Alex (1983): Statius and the Silvae. Poets, patrons and epideixis in the Graeco-Roman world (ARCA 9), Liverpool, Francis Cairns.

Herzog, August (1881): Stati Epithalamium (Silv. I, 2), Diss. Leipzig, Breitkopf und Haertel.

Herzog, R., und P. Lebrecht Schmidt (1989): Handbuch der lateinischen Literatur der Antike. V. Restauration und Erneuerung: 284-374 n. Chr., Munich, Beck.

Kamerbeek, J. C. (1978): The Plays of Sophocles. III. The Antigone, Leiden, E. J. Brill.

Laguna, Gabriel (1988): Estudio literario de la poesía 67 de Catulo, Tesis de Licenciatura (inédita), Sevilla, Universidad de Sevilla.

Laguna, Gabriel (1989): «Dos imágenes matrimoniales en el episodio de Dafne y Apolo (Ov. met. I 452-567): sex crines y las teas de la flamma amoris", Anuario de Estudios Filológicos 12, pp. 133-143.

Laguna, Gabriel (1990): "La Silva 5.4 de Estacio: plegaria al Sueño», Habis 21, pp. 121-138.

Laguna, Gabriel (1992): Estacio, Silvas III. Introducción, edición crítica, traducción y comentario, Madrid-Sevilla, Fundación Pastor de Estudios ClásicosUniversidad de Sevilla.

Laguna, Gabriel (en prensa): "La inversión horaciana de los géneros epidícticos tradicionales: el epitalamio (Carm. 3, 6, 17-48)", en Actas del Congreso "Bimilenario de Horacio" (Salamanca, 1-4 de diciembre de 1992), Salamanca.

Lasserre, F. (1946): La figure d'Eros dans la poésie grecque, Lausana, Impr. réunies.

Lasso de la Vega, José (1990): «El himno al Amor de Sófocles (Antígona, 781800)", en De la Grecia arcaica a la Roma imperial, Cursos de Verano de El Escorial 1989, Madrid, Universidad Complutense.

Lattimore, Richmond (1962): Themes in Greek and Latin epitaphs, Urbana, University of Illinois Press.

Lohrisch, Hermann (1905): De Papinii Statii Silvarum poetae studiis rhetoricis, Diss. Hallis, C. A. Kaemmerer.

Lotito, Gianfranco (1974-75): «Il tipo etico del liberto funzionario di corte (Stazio, Silvae III 3 e V 1)", Dialogi di Archeologia 8, pp. 275-383.

Luque Moreno, Jesús (1980): Séneca. Tragedias, II (Biblioteca Clásica Gredos 27), Madrid, Gredos.

Lutz, Cora E. (1947): "Musonius Rufus, 'The Roman Socrates'», Yale Classical Studies 10, pp. 3-147.

Markland, Jer (1827, ): P. Papinii Statii libri quinque Siluarum, Dresde-Londres, Libraria Wagneria.

Marrou, H. I. $\left(1965_{2}\right)$ : Histoire de l'Éducation dans l'Antiquité, París, Éditions du Seuil. 
McKeown, J. C. (1989): Ovid: Amores. Text, prolegomena and commentary. Volume II. A commentary on Book one, Leeds, Francis Cairns.

Menéndez Pelayo, Marcelino (1950): Bibliografia Hispano-Latina Clásica, vol. III, Santander, C.S.I.C.

Morelli, C. (1910): "L'epitalamio nella tarda poesia latina», SIFC 17, pp. 31942.

Müller, G. (1967): Sophokles. Antigone, Heidelberg, Winter.

Müller, Heinz Martin (1980): Erotische Motive in der griechischen Dichtung bis auf Euripides, Hamburgo, Buske.

Müller, Henri (1894): Studia Statiana, Diss. Berlín, R. Heinrich.

Newmyer, S. T. (1979): The Silvae of Statius. Structure and theme, Leiden, E. J. Brill.

Nisbet, R. G. M. and Margaret Hubbard (1970): A commentary on Horace: Odes. Book I, Oxford, Clarendon Press.

Nisbet, R. G. M. and Margaret Hubbard (1978): A commentary on Horace: Odes. Book II, Oxford, Clarendon Press.

Norden, Eduard (1913): Agnostos Theos. Untersuchungen zur Formengeschichte religiöser Rede, Leipzig-Berlín (reimp. Stuttgart, Teubner, 1956).

Pavlovskis, Zoja (1965): "Statius and the late Latin epithalamia», CPh 60, pp. 164-177.

Pavlovskis, Zoja (1972): The influence of Statius upon Latin literature before the tenth century, Tesis Doctoral (inédita), Ithaca (Nueva York), Cornell University.

Pernot, Laurent (1986): «Les topoi de l'éloge chez Ménandros le rhéteur», $R E G$ 470-71, pp. 33-53.

Pichon, René (1902): Index verborum amatoriorum, París, Librairie Hachette (reimp. Hildesheim, Georg Olms, 1966).

Radt, Stefan (1977): Tragicorum Graecorum Fragmenta. Vol. 4. Sophocles, Gotinga, Vandenhoeck \& Ruprecht.

Radt, Stefan (1985): Tragicorum Graecorum Fragmenta. Vol. 3. Aeschylus, Gotinga, Vandenhoeck \& Ruprecht.

Ramírez de Verger, Antonio (1986): «Una lectura de los poemas a Lesbia y a Cintia", EC 90, pp. 69-83.

Ramírez de Verger, Antonio (1987): "La elegía I 9 de Tibulo», Veleia 4, pp. 335-346.

Ramírez de Verger, Antonio (1989): Propercio. Elegias (BCG 131), Madrid, Gredos.

Ramírez de Verger, Antonio, y Francisco Socas (1991): Publio Ovidio Nasón. Obra amatoria, I. Amores, Madrid, C.S.I.C.

Reche Martínez, M. ${ }^{a}$ Dolores (1991): Teón. Hermógenes. Aftonio. Ejercicios de retórica (BCG 158), Madrid, Gredos.

Reichel, Georg (1909): Quaestiones progymnasmaticae, Diss. Leipzig, R. Noske.

Roberts, Michael (1989): "The use of myth in Latin epithalamia from Statius to Venantius Fortunatus", TAPhA 119, pp. 321-348.

Russell, D. A. and N. G. Wilson (1981): Menander Rhetor, Oxford, Clarendon Press.

Sauter, Franz (1934): Der römische Kaiserkult bei Martial und Statius, StuttgartBerlin, W. Kohlhammer.

Skutsch, O. (1985): The Annals of $Q$. Ennius, Oxford, Clarendon Press.

Socas, Francisco (1985): "Venus volgivaga o El amor tornadizo y plebeyo", Er 2, pp. 7-17.

Spengel, Leonard (1854): Rhetores Graeci, vol. II, Teubner, Leipzig.

Spengel, Leonard (1856): Rhetores Graeci, vol. III, Teubner, Leipzig.

Thomas, Richard (1988): Virgil. Georgics, vols. I y II, Cambridge, University Press. 
Usener, Hermann et Ludwig Radermacher (1905): Dionysius Halicarnessensis. Opuscula, vol. II, Leipzig, Teubner.

Verstraete, Beert C. (1983): "Originality and mannerism in Statius' use of myth in the Silvae", $A C$ 52, pp. 195-205.

Vessey, David (1972): "Aspects of Statius' Epithalamion", Mnemosyne 25, pp. 172-187.

Vessey, David (1973): Statius and the Thebaid, Cambridge, University Press.

Vessey, David (1986): "Transience preserved: style and theme in Statius' 'Silvae'», $A N R W$ II 32, 5, pp. 2754-2803.

Viljamaa, Toivo (1969): Studies in Greek encomiastic poetry of the early Byzantine period (Commentationes humanarum litterarum, Societas Scientiarum Fennica, vol. 42, n. 4), Helsinki.

Vollmer, Friedrich (1898): P. Papinii Statii Silvarum Libri, Leipzig, Teubner (reimp. Hildesheim, Georg Olms, 1971).

Wheeler, Arthur Leslie (1930): "Tradition in the Epithalamion", AJPh 51, pp. 205-223.

Williams, Gordon (1958): "Some aspects of Roman marriage ceremonies and ideals", JRS 48, pp. 16-29.

Yardley, J. C. (1978): "The elegiac paraclausithyron», Eranos 76, pp. 19-34. 